\title{
A questão agrária na Microrregião de União da Vitória/PR: o latifúndio e seus desdobramentos geográficos
}

\author{
The agrarian issue at união da vitória/pr micro region : the large state and its geographical \\ unfoldings. \\ La cuestión agraria en la región noreste de união da vitória-pr: el folwark y sus desarrollos \\ espaciales
}

\section{Silas Rafael da Fonseca ${ }^{1}$}

Recebido em 04/2017 - aceito em 07/2017.

\begin{abstract}
Resumo
O artigo parte do entendimento de que compreender a questão agrária na microrregião de União da Vitória perpassa pela atualidade do conceito de latifúndio. Para tanto, refutamos a carga ideológica do discurso de desenvolvimento econômico gerador de divisas da monocultura, isso porque a agricultura capitalista tem gerado concentração de terra e renda na região, provocando pobreza e a desagregação de modos de vida. Assim, o texto busca apontar alguns elementos de como se expressa territorialmente a monocultura de árvores, revelada no latifúndio produtivo, na microrregião de União da Vitória, e quais suas implicações para as populações do campo e da cidade. Como suporte teórico a análise e entendimento da questão agrária perpassa pela compreensão do desenvolvimento do capitalismo no campo, que se manifesta territorialmente de modo contraditório e combinado. Com base nessa perspectiva teórica e somada a análise de dados preliminares (apresentados no decorrer do artigo), observamos, que a agricultura capitalista, expressa no latifúndio improdutivo e no latifúndio produtivo (agronegócio), não é sinônimo de desenvolvimento local e regional.
\end{abstract}

Palavras-Chave: Questão Agrária; Latifúndio; Monocultivo de Árvores.

\begin{abstract}
The article starts from the necessity that understanding the agrarian issue at União da Vitória microregion passes through the actuality of large state concept. Therefore, it's refuted the ideological burden of the discourse of economic development creator of monoculture boundary, because the capitalist agriculture has generated the land concentration and income in the region, causing poverty and breakdown in the lifestyle. Thus, the text points out some elements of how it is expressed territorially the trees monoculture, revealed at the productive large state, at União da Vitória microregion, and what are its implications to the city and rural population. As a theoretical basis, the analysis and understanding of the agrarian issue passes through the understanding of development of field capitalism, that manifests territorially in a contradictory and combined way. Based on this theoretical perspective, added to preliminary data analysis (presented along this article), it is observed that the capitalist agriculture expressed in the improductive and productive large state (agribusiness), is not a synonym of local and regional development.
\end{abstract}

Key-words: Agrarian Issue, Large State, Trees Monoculture.

\section{Resumen}

El artículo parte del entendimiento de que comprender la cuestión agraria en la microrregión de União da Vitória sobrepasa por la actualidad del concepto de latifundio. Para ello, refutamos la carga ideológica del discurso de desarrollo económico generador de divisas del monocultivo, porque la agricultura capitalista ha generado concentración de tierra y renta en la región, provocando pobreza y

Geografia (Londrina) v. 26, n. 1, p. $173-187$, jan/jun, 2017. 
disgregación de modos de vida. Así, el texto apunta algunos elementos de cómo se expresa territorialmente la monocultura de árboles, revelada en el latifundio productivo, en la microrregión de União da Vitória, y cuáles sus implicaciones para las poblaciones del campo y de la ciudad. Como soporte teórico, el análisis y entendimiento de la cuestión agraria atraviesa la comprensión del desarrollo del capitalismo en el campo, que se manifiesta territorialmente de modo contradictorio y combinado. En base a esta perspectiva teórica y sumada al análisis de datos preliminares (presentados en el transcurso del artículo), observamos que la agricultura capitalista, expresada en el latifundio improductivo y en el latifundio productivo (agronegocio), no es sinónimo de desarrollo local y regional.

Palabras Clave: Cuestión Agraria; Latifundio; Monocultivo de Árboles.

\section{INTRODUÇÃO}

A área estudada (Microrregião Geográfica de União da Vitória) é composta pelos seguintes municípios: Bituruna, Cruz Machado, General Carneiro, Paula Freitas, Paulo Frontin, Porto Vitória e União da Vitória, tem como principal característica no campo, a produção da monocultura de árvores (pinus e eucalipto), condição que gera desdobramentos sociais, econômicos e ambientais, tanto para populações do campo, quanto da cidade.

O artigo parte do entendimento de que compreender a questão agrária na microrregião de União da Vitória, perpassa pela atualidade do conceito de latifúndio. Para tanto, refutamos a carga ideológica do discurso de desenvolvimento econômico gerador de divisas da monocultura, isso porque a agricultura capitalista tem gerado concentração de terra e renda na região. Assim, o artigo busca apontar alguns elementos de como se expressa territorialmente a monocultura de árvores, revelada no latifúndio improdutivo, na microrregião de União da Vitória, e quais suas implicações para as populações do campo e da cidade.

O método que sustenta esse trabalho é materialismo histórico dialético, de modo que se busca compreender as contradições que se estabelecem na sociedade, com intuito de descortinar a realidade de forma mais profunda e precisa.

A construção da abordagem crítica radical tem seu fundamento na crítica ao positivismo e à ciência dita burguesa. Com isso, a Geografia Crítico Radical propõe que a ciência tenha a função de mudança na sociedade, ou seja, trata-se da ciência com cunho político e social. Uma das premissas de tal abordagem é que não existe neutralidade científica, de modo que o pesquisador não consegue se separar de seu lugar na sociedade e de suas visões políticas e sociais, ou seja, enquanto pesquisadores, somos carregados de pressupostos axiológicos, dos quais não nos apartamos na prática de pesquisa e na interpretação teórico/analítica/metodológica da realidade.

Toda pesquisa se realiza através da interpretação do pesquisador, sem que ele se coloque como neutro, já que nas ciências sociais e humanas, em significativa parcela das 
pesquisas, "o sujeito está implicado no objeto". Sendo assim, impossível falar em neutralidade científica.

Também o cientista jamais pode dizer-se neutro, a não ser por ingenuidade ou por uma concepção mítica do que seja ciência. A Objetividade que podemos reconhecer-lhe, não pode ser concebida a partir do modelo de um conhecimento reflexo. A imagem do mundo que as ciências elaboram, de forma alguma pode ser confundida com uma espécie de instantâneo fotográfica da realidade tal como ela é percebida. De uma forma ou de outra, ela é sempre uma interpretação (JAPIASSU, 1975, p.11).

A pesquisa, no nosso entendimento, sempre está relacionada com a interpretação de mundo pesquisador, seus posicionamentos políticos, sociais e culturais. Assim, como aponta Japiassu (1975), ela não pode ser confundida com uma fotografia instantânea da realidade.

Neutralidade científica, que está na base do positivismo, de modo que a partir de sua crítica vai gerar o surgimento e consolidação da Geografia Crítico Radical. Contudo, pensase que o fato de se posicionar diante do objeto de pesquisa, bem como a escolha de determinadas linhas teóricas e de abordagens metodológicas já indicam que o pesquisador não é neutro, ou seja, já se está tomando uma posição em detrimento de outras possíveis.

Não obstante, o materialismo histórico dialético faz do pesquisador não apenas um interlocutor dos sujeitos pesquisados, mas faz da pesquisa um instrumento para a mudança da sociedade e a busca de um mundo mais justo e igualitário. Moraes (2007) colabora com tal entendimento.

[...] o designativo de crítica diz respeito, principalmente, a uma postura frente à realidade, frente à ordem constituída. São os autores que se posicionam por uma transformação da realidade social, pensando o seu saber como uma arma desse processo. São, assim, os que assumem o conteúdo político de conhecimento científico, propondo uma Geografia militante, que lute por uma sociedade mais justa. São os que pensam a análise geográfica como um instrumento de libertação do homem (MORAES, 2007, p.119).

Deste modo, através do materialismo histórico dialético e da abordagem Crítico Radical na Geografia Agrária, a metodologia deste trabalho baseia-se na pesquisa qualiquantitativa, ou seja, levantamento, análise e compreensão de dados qualitativos e quantitativos farão parte do trabalho

Nessa perspectiva analisamos os dados de produção de madeira na microrregião de União da Vitória, e propomos a compreensão das implicações do latifúndio improdutivo e produtivo e seus desdobramentos no que concerne os problemas sociais, econômicos e ambientais na área de estudo.

Deste modo, buscamos contribuir com o refazer epistemológico da ciência geográfica ao trazer para reflexão um fenômeno geográfico pouco discutido na referida 
região. Vale ressaltar, que o caráter de ineditismo da abordagem, refere-se, sobretudo, ao esforço em avançar no entendimento conceitual, analítico e empírico do latifúndio, rompendo com o discurso de produção, geração de emprego-renda e desenvolvimento econômico, apontando, suas contradições e implicações sociais, econômicas e ambientais.

Como suporte teórico partimos da análise e entendimento da questão agrária, ou seja, a compreensão do desenvolvimento do capitalismo no campo. "O estudo da agricultura brasileira deve ser feito levando em conta que o processo de desenvolvimento do modo capitalista de produção no território brasileiro é contraditório e combinado" (OLIVEIRA, 2004, p. 35-36).

Com base nessa perspectiva teórica e somada a análise de dados preliminares (Índice de Desenvolvimento Humano Municipal, Estrutura fundiária, Taxa de Pobreza entre outros), observamos, que a agricultura capitalista, expressa no latifúndio improdutivo e no latifúndio produtivo (agronegócio), não é sinônimo de desenvolvimento local e regional. 0 alardeado discurso de geração de emprego e renda, na prática mostra-se falacioso, agravando as desigualdades. A agricultura capitalista também não é capaz de aliar produção e preservação ambiental, sendo igualmente perverso o discurso em torno do desenvolvimento sustentável, que se mostra intangível sob a lógica do modo de produção de capitalista, sobretudo, em regiões onde está presente a monocultura do árvores (pinus e eucalipto), da cana de açúcar, soja e milho, culturas que constantemente são relacionadas com a "modernização" da agricultura, geração de empregos e renda e que na prática contribuem para puxar para baixo indicadores sócio econômicos, como o IDH - Índice e Desenvolvimento Humano, à medida que ocasionam, por exemplo, a concentração de renda, em paralelo com a concentração fundiária

Compreendemos que a produção da monocultura de árvores na região estudada tem sido uma das principais geradoras de pobreza e expulsão no campo e na cidade, por meio de constantes processos de desterritorialização. A seguir apresentamos o Tabela $1 \mathrm{com}$ dados do IDHM para contribuir com a problematização a respeito da estrutura socioeconômica da mircrorregião.

Ao analisar os dados da tabela, podemos perceber que de todos os municípios da microrregião, União da Vitória tem o melhor IDHM, com 0,740, indicador que fica acima da média nacional, porém, abaixo da média paranaense. O município com menor IDHM é General Carneiro, (0,652), seguido por Cruz Machado $(0,664)$ e Bituruna $(0,667)$. Destacamos que esses baixos índices permanecem no quesito renda, onde todos os municípios estão abaixo da média nacional e estadual. No IDHM longevidade, apenas os municípios de Porto Vitória e Paulo Frontin estão abaixo da média brasileira e estadual, enquanto Bituruna e General Carneiro estão acima da média nacional, mas abaixo do indicador estadual. Quando voltamos para os dados de educação, percebemos que apenas 
União da Vitória está acima da média nacional e paranaense (União da Vitória é onde estão as universidades privadas e a única universidade pública da microrregião - UNESPAR, assim se justifica um melhor IDHM na educação), enquanto Paulo Frontin está acima da média nacional e abaixo da média estadual.

Tabela 1: Índice de Desenvolvimento Humano Municipal (IDHM) - Brasil, Paraná e Municípios da Microrregião de União da Vitória (2010)

\begin{tabular}{lllll}
\hline & IDHM & IDHM Renda & IDHM Longevidade & IDHM Educação \\
\hline Brasil & 0,727 & 0,739 & 0,816 & 0,637 \\
Paraná & 0,749 & 0,757 & 0,83 & 0,668 \\
Bituruna & 0,667 & 0,645 & 0,829 & 0,556 \\
Cruz Machado & 0,664 & 0,635 & 0,845 & 0,545 \\
General Carneiro & 0,652 & 0,638 & 0,816 & 0,532 \\
Paula Freitas & 0,717 & 0,699 & 0,847 & 0,622 \\
Paulo Frontin & 0,708 & 0,688 & 0,806 & 0,639 \\
Porto Vitória & 0,685 & 0,674 & 0,796 & 0,6 \\
União da Vitória & 0,740 & 0,713 & 0,837 & 0,68 \\
\hline
\end{tabular}
Fonte: Atlas Brasil, 2016.

Diante disso, entendemos que o discurso da monocultura de árvores (agricultura capitalista/agronegócio), constantemente divulgado como geradora de divisas, não se expressa na região, o pouco trabalho gerado nas indústrias e no campo é de baixa qualificação e salário reduzido, gerador de concentração de terras e pobreza no campo e na cidade. Esse processo se mostra histórico na microrregião de União da Vitória, já que a exploração da madeira nativa e da monocultura de árvores se estende desde a Guerra do Contestado ${ }^{2}$.

Desde a guerra, os camponeses da região vêm sofrendo com o processo de exploração da madeira. Expulsos do campo e perdem/sofrem desagregação de seu modo de vida. Esse processo não termina com a guerra, de modo que permanece com a chegada da monocultura de árvores, através, por exemplo, da inviabilização da produção camponesa pelo ataque de animais e nas épocas de corte da madeira pela destruição das estradas para o escoamento da mercadoria. Esses impactos também podem ser observados na cidade, principalmente pela falta de emprego, sobretudo, para as mulheres trabalhadoras que tem dificuldade em se inserir no mercado de trabalho da madeira, como serralherias, madeireiras e empresas de plantio de árvores entre outras funções ligadas à monocultura de árvores.

\section{A PERMANÊNCIA DO LATIFÚNDIO}

"O processo de desenvolvimento do modo capitalista de produção tem necessariamente que ser entendido no seio das realidades históricas concretas, ou seja, no seio da formação econômico-social capitalista" (OLIVEIRA, 1986, p. 28). 
O campo brasileiro é marcado pela contradição. Trata-se das relações de produção capitalistas (latifúndio produtivo/agronegócio) e das relações de produção não capitalistas (campesinato e latifúndio improdutivo), "o próprio capital cria relação capitalistas e nãocapitalistas de produção" (OLIVEIRA, 1986, p. 11).

Assim, o desenvolvimento contraditório do modo capitalista de produção, particularmente em sua etapa monopolista, cria, recria, domina relação nãocapitalistas de produção como, por exemplo, o campesinato e a propriedade capitalista da terra. A terra sob o capitalismo tem que ser entendida como renda capitalizada. (OLIVEIRA, 1986, p. 12).

No Brasil, a partir das décadas de 1960-1970, no contexto histórico da formação econômico-social capitalista, as relações de produção capitalistas têm se configurado em torno da agricultura capitalista, que tem como sinônimo o "agronegócio", expresso na tecnificação do campo e na transformação do território. Na esfera produtiva, destacam-se as monoculturas de árvores, pastagens, cana de açúcar, milho e soja como sendo de grande importância para o desenvolvimento econômico. Porém, quando vamos a campo, com o objetivo de conhecer e compreender a realidade pelo alinhamento teórico da questão agrária, percebemos que esse discurso não se concretiza em muitas regiões do estado do Paraná, como é o caso da microrregião de União da Vitória. Assim, o conceito de latifúndio permanece como fundante para entender essa realidade, como nos aponta Paulino (2015).

\begin{abstract}
Inquerir a produção acadêmica a fim de verificar se esses preceitos estão sendo considerados pelos que afirmam ter havido a substituição do latifúndio pela empresa rural não deixa de ser um exercício de rigor metodológico necessário para explicar ideologias travestidas de verdades científicas. Como lembra Fernandes (2006), a expressão "agronegócio" tem servido como saída linguística para escapar ao debate necessário sobre o Latifúndio produtivo e, nessas condições, tão passível de desapropriação quanto o improdutivo. (PAULINO, 2015, p. 86).
\end{abstract}

A palavra latifúndio tem desaparecido do nosso vocabulário e cada vez mais o termo "agronegócio" tem ganhado a academia e a mídia, mesmo que, conforme OLIVEIRA (2003), o Brasil seja um país que apresenta elevadíssimos índices de concentração de terra, de modo que aqui estão os maiores latifúndios da história da humanidade.

Assim, concordamos com Fabrini (2008, p. 60) quando diz que "o agronegócio foi colocado pelos segmentos dominantes da sociedade como modelo de 'desenvolvimento' para a agricultura brasileira, sendo interpretado como empresas rurais altamente produtivas". Contudo, a agricultura capitalista, expressa no "agronegócio", para muito além do discurso propalado pelas elites ruralistas-empresariais, se apresenta de três formas: o latifúndio improdutivo (por extensão) e o latifúndio produtivo. Compreendemos o latifúndio 
produtivo a partir do não cumprimento da função social da terra, como nos mostra Marés (2003).

A constituição define como requisitos para que uma propriedade rural (leiase terra) cumpra a função social: 1) aproveitamento racional do solo; 2) utilização adequada dos recursos naturais disponíveis e preservação do meio ambiente; 3) observação das disposições que regulam as relações de trabalho; 4) exploração que favoreça o bem-estar dos proprietários e trabalhadores. (MARES, 2003, p.116).

Todo imóvel rural deve cumprir a função social, simultaneamente os quatro itens presentes na lei, assim, o imóvel que não cumprir essas determinações está passível de desapropriação. Acreditamos que atualmente o latifúndio produtivo não consegue cumprir tais determinações, o que contribui para a sua conceituação, ou seja, mesmo que esteja gerando renda a partir de sua produção (o que muitas vezes pode ser questionado como tal renda é gerada), não consegue cumprir a função social e ambiental da terra. Como exemplo, pode-se analisar o monocultivo de árvores, que vem cada vez mais mostrando suas consequências sociais e ambientais, como, por exemplo, os impactos gerados pelo desaparecimento de nascentes, o desiquilíbrio da fauna e da flora local e a presença em diversas localidades do não cumprimento das normas trabalhistas. De tal modo, entendemos que o latifúndio produtivo tem gerado impactos tão significativos à sociedade, quando o latifúndio improdutivo e, por extensão, vamos novamente recorrer a Marés (2003), para entender que o não cumprimento da função social da terra faz com que essas áreas sejam passíveis de desapropriação.

A constituição não indica com clareza qual o castigo que terá um proprietário que não faz a terra cumprir sua função social, mas ele parece óbvio: o proprietário tem a obrigação de cumprir o determinado, é um dever do direito, e quem não cumpre seu dever, perde seu direto. Quem não paga o preço não recebe a coisa, quem não entrega a coisa não pode reivindicar o preço. Quer dizer, o proprietário que não obra no sentido de fazer cumprir a função social de sua terra, perde-a, ou não tem direto a ela. (MARÉS, 2003, p.117).

O imóvel pode ou não ser produtivo. Se não cumprir a função social da terra, o seu detentor não tem mais direito legítimo sobre ela. No Paraná e na área de estudo existe a presença do latifúndio produtivo e improdutivo que não cumprem a função social da terra e, se não cumprem a função social da terra, devem voltar a pertencer a União e serem destinados à reforma agrária.

É sabido que nosso legislador não tem usado desse mecanismo contra os latifundiários, mas, ao contrário os índices de produtividade, se mantém sem atualização, 
pela pressão política da "bancada ruralista". Assim, a improdutividade se mantém no campo brasileiro aliada ao não cumprimento da função social.

Nesse contexto, a palavra "agronegócio" acabou por esconder a falsa produtividade do campo brasileiro. A agricultura capitalista e a agricultura camponesa nem sequer são tratadas de forma diferente quando se trata os dados de produtividade, ou seja, a (não) produção do latifundiário e a produção camponesa são somadas, isto é, toda produção no campo entra nos dados do "agronegócio" e somadas com outras atividades, como as do setor de serviços, insumos e indústria. A Tabela 2, ajuda-nos a entender como se compõem o PIB do "agronegócio".

Tabela 2: Produto Interno Bruto do agronegócio brasileiro (PIB) em relação ao PIB Total do

\begin{tabular}{ll}
\multicolumn{2}{c}{ Brasil - 2015} \\
\hline Agronegócio & 2015 \\
A) Insumos & $2,56 \%$ \\
B) Agropecuária & $6,40 \%$ \\
C) Indústria & $5,90 \%$ \\
D) Serviços & $6,61 \%$ \\
Total (A+B+C+D) & $21,46 \%$ \\
\hline \multicolumn{2}{c}{ Fonte: Cepea/USP e CNA }
\end{tabular}

Como podemos perceber, em 2015, o PIB da agropecuária (agricultura e pecuária juntas, no texto quando se refere a agricultura já aponta-se para as duas) foi de apenas $6,40 \%$, sendo o restante, que compõe a conta do agronegócio, além da produção camponesa (já inclusa nos dados da agropecuária), o setor de serviços (comércio em geral, transportes, entre outros), além dos insumos, e indústria. Entendemos que caso no Brasil não existisse a agricultura capitalista, esses outros fatores - serviços, insumos e indústria continuariam a existir em nossa economia, já que vários dados e pesquisas têm demostrado a eficiência da agricultura camponesa ${ }^{4}$.

É interessante pensar que quando se calcula os dados da agricultura capitalista (agronegócio) se soma a produção da agricultura camponesa, mas, quando se fala em concessão de crédito rural, os dois grupos são divididos entre agricultura capitalista (latifúndio produtivo "agronegócio") e agricultura camponesa ("agricultura familiar").

Percebemos que o discurso gerador de divisas da agricultura capitalista não é demostrado, quando se analisa o PIB da agricultura. Podemos dizer que a agricultura capitalista produziu menos que $6,40 \%$ do PIB nacional em 2015, já que nela está incluída a produção da agricultura camponesa. 
[...] se por um lado, o agronegócio é entendido como grande propriedade rural produtiva, por outro, é responsável pela pobreza, miséria, degradação ambiental, violências, dentre outras mazelas e barbáries. Diferentemente do latifúndio do passado que "excluía" pela não-produção, agora o agronegócio "exclui" pela produção! (FABRINI, 2008, p. 36)

Deste modo, compreender a questão agrária na microrregião de União da Vitória passa, necessariamente, pelo entendimento de como a terra está distribuída, pela análise da dinâmica produtiva, pela identificação nas transformações no território e no ambiente e pelos desdobramentos aos modos de vida, às condições de existência e de reprodução social.

\section{AS IMPLICAÇÕES DO LATIFÚNDIO NA MICRORREGIÃO DE UNIÃO DA VITÓRIA}

Ao apontarmos para a presença do latifúndio produtivo e improdutivo na microrregião de União da Vitória devemos necessariamente analisar os dados relacionados à estrutura fundiária tabulados na Tabela 3.

Quando analisamos a estrutura fundiária da microrregião de União da Vitória percebemos o processo de concentração de terras. A tabela 3 permite verificar que existe uma discrepância dos dados, isso porque, os imóveis com menos de 10 hectares representam $28,92 \%$ dos imóveis declarados, porém, detém apenas $4,29 \%$ da área, já os imóveis com mais de 1000 hectares são 0,42\% do total imóveis, contudo, abocanham 23,69\% das terras declaradas na microrregião. Isso significa que 61 imóveis controlam quase um quarto das terras.

Tabela 3 -Estrutura fundiária microrregião de União da Vitória -PR - 2014

\begin{tabular}{|c|c|c|c|c|c|}
\hline Classe de área & Número de Imóveis & $\begin{array}{l}\% \text { de } \\
\text { imóveis }\end{array}$ & Área & $\begin{array}{ll}\% & \mathrm{de} \\
\text { área } & \\
\end{array}$ & $\begin{array}{l}\text { Área } \\
\text { média }\end{array}$ \\
\hline 0 a menos de 10 & 4230 & 28,92 & 24920,0 & 4,29 & 5,9 \\
\hline $\begin{array}{l}10 \text { a menos de } 50 \\
50 \text { a menos de }\end{array}$ & 8767 & 59,94 & 197070,1 & 33,92 & 22,5 \\
\hline 100 a menos de & 975 & 6,67 & 65662,2 & 11,30 & 67,3 \\
\hline 250 & 317 & 2,17 & 43290,6 & 7,45 & 136,6 \\
\hline 250 a menos 1000 & 276 & 1,89 & 112368,5 & 19,34 & 407,1 \\
\hline Mais de 1000 & 61 & 0,42 & 137620,6 & 23,69 & 2256,1 \\
\hline Total & 14626 & 100 & 580931,9 & 100 & 39,7 \\
\hline
\end{tabular}

Fonte: INCRA, 2014.

Quando observamos o módulo fiscal da região percebemos que com exceção de União da Vitória que o módulo é de 20 hectares, nos demais municípios é de 24 hectares. Assim parte significativa dos imóveis entre 0 a 50 hectares são classificados como minifúndios, pela classificação dos módulos fiscais isso significa que a área é menor que a considerada 
necessária para a manutenção da família. Quando analisamos a média dos imóveis nessas classes de área, menos que 10 hectares e de 10 a menos de 50 hectares, a média do primeiro é 5,9 hectares e do segundo 22,5 hectares, caracterizando-se como minifúndios, portanto, consideradas áreas economicamente inviáveis.

Tabela 4: Porcentagem de área declarada se comparada a área do município na microrregião de União da Vitória-2014

\begin{tabular}{cccc}
\hline Município & $\begin{array}{c}\text { Área Total } \\
\text { Declarada em } \\
\text { hectares }\end{array}$ & $\begin{array}{c}\text { Área municipal } \\
\text { total em } \\
\text { hectares }\end{array}$ & $\begin{array}{c}\text { Porcentagem de } \\
\text { área declarada se } \\
\text { comparada a área } \\
\text { do município }\end{array}$ \\
\hline Bituruna & $135.412,7$ & $121.883,3$ & 111,1 \\
Cruz Machado & $147.269,1$ & $147.737,2$ & 99,7 \\
General Carneiro & $115.027,1$ & $107.201,3$ & 107,3 \\
Paula Freitas & $40.977,0$ & $429.01,3$ & 95,5 \\
Paulo Frontin & $36.321,0$ & $367.28,4$ & 98,9 \\
Porto Vitória & $18.196,4$ & $213.14,2$ & 85,4 \\
União da Vitória & $69.604,1$ & $71.356,5$ & 97,5 \\
\hline
\end{tabular}

Fonte: INCRA, 2014 e IPARDES, 2016

Outro processo que apontamos é a superdeclaração de terras na microrregião, quando observamos a Tabela 4 que compara a área total dos municípios com a área declarada.

Quando observamos a área total dos municípios comparada com a área total declarada de imóveis, percebemos que, em Bituruna e General Carneiro, existe um processo de superdeclaração, já que quando consideramos a área total do município, pelas dificuldades em conseguir dados consistentes somente da área agricultável, não retiramos desses indicadores corpos hídricos, área urbana e unidades de conservação. Mesmo assim percebemos municípios como Bituruna com uma porcentagem de $111,1 \%$ da área declarada se comparada a área total do município, ou seja, $11,1 \%$ a mais de área declarada, na mesma condição está General Carneiro, com 7,3\% a mais de área declarada. Os demais municípios estudados apresentam áreas declaradas próximas de 100\%. Sobre as superdeclarações Paulino (2015) contribui para essa reflexão na escala nacional.

Importante observar que isso corresponde a 5,8 Brasis [discorrendo sobre auto declaração de imóveis do INCRA 2011] ou à soma do continente americano mais o território da União Europeia e, de quebra, mais o correspondente a $78 \%$ da Índia! Que não sejamos ingênuos o suficiente para crer que se trata-se de meros devaneios de quem segue com a certeza da impunidade no propósito de se assenhorar do planeta! Muitos desses pretensos proprietários estão fazendo uso dessa condição para ganhar 
dinheiro ilícito, seja forjado garantias para operações financeiras, seja sacando madeira nativa, dentre outras possibilidades de enriquecer por meio do esbulho real e virtual da terra (PAULINO, 2015, p. 81).

Como vem acontecendo em escala nacional, esse processo se expressa também nas escalas regionais e municipais. Assim, o processo de declarações de áreas maiores, do que realmente são as propriedades, possibilita com que esses ditos proprietários, de posse do Certificado de Cadastro de Imóvel Rural (CCIR), possam usar a área declarada como garantia de financiamentos ou para se apossar de áreas públicas, para exploração ou venda. Ainda mais, se avaliarmos o processo histórico de apropriação da terra na microrregião estudada, que foi palco da Guerra do Contestado, onde muitas das terras próximas à ferrovia São Paulo-Rio Grande foram apropriadas de forma ilícita pelo capital monocultor de árvores.

Quando apontamos para o principal fator econômico da região, o discurso dos entusiastas do capital e políticos locais é de que o setor madeireiro é considerado o grande gerador de renda na microrregião. Não concordamos com esse posicionamento já que as repercussões territoriais não demostram essa importância econômica, aqui podemos destacar um de seus rebatimentos geográficos, que é o percentual de área plantada por município.

Tabela 5: Percentual de área plantada de Silvicultura (2015) se comparado a área declarada (INCRA 2014)

\begin{tabular}{llll}
\hline Município & Área Total Declarada & Área plantada Silvicultura & $\%$ \\
\hline Bituruna & $135.412,7$ & 23.000 & 17,0 \\
Cruz Machado & $147.269,1$ & 22.000 & 14,9 \\
General Carneiro & $115.027,1$ & 28.185 & 24,5 \\
Paula Freitas & $40.977,0$ & 5.100 & 12,4 \\
Paulo Frontin & $36.321,0$ & 3.820 & 10,5 \\
Porto Vitória & $18.196,4$ & 4.500 & 24,7 \\
União da Vitória & $69.604,1$ & 11.000 & 15,8 \\
\hline
\end{tabular}

Fonte: IBGE, 2015 e INCRA, 2014.

A tabela mostra a porcentagem da área plantada em relação ao total de área declarada. Percebemos como a silvicultura tem um forte destaque na região estudada, como nos municípios de General Carneiro e Porto Vitória onde, em 2014, ocupava quase 1/4 das áreas declaradas. Nos demais municípios a monocultura de árvores igualmente representa um elemento importante para a configuração geográfica da microrregião. Esses dados, contribuem para entender como se expressa a produção no campo na microrregião de União da Vitória.

Assim, compreendemos que a produção da monocultura de pinus e eucalipto na região, tem sido uma das principais geradoras de pobreza e expulsão no campo e na 
cidade. Como já apontamos na tabela 1 quando analisamos o IDHM dos municípios, outro dado que contribui com nossa análise é a concentração de renda nos munícipios.

Tabela 7: Percentual da renda apropriado pelos $20 \%$ mais pobres e mais ricos - Brasil, Paraná e municípios da Microrregião de União da Vitória

\begin{tabular}{lll}
\hline & $\begin{array}{l}\text { Percentual da renda apropriado } \\
\text { pelos } 20 \% \text { mais pobres }\end{array}$ & $\begin{array}{l}\text { Percentual da renda apropriado } \\
\text { pelos 20\% mais ricos }\end{array}$ \\
\hline Brasil & 2,41 & 63,4 \\
Paraná & 3,77 & 58,57 \\
Bituruna & 3,5 & 53,01 \\
Cruz Machado & 2,26 & 56,52 \\
General Carneiro & 4,42 & 52,85 \\
Paula Freitas & 2,79 & 61,46 \\
Paulo Frontin & 3,38 & 55,1 \\
Porto Vitória & 4,84 & 48,89 \\
União da Vitória & 4,3 & 53,3 \\
\hline
\end{tabular}

Fonte: Atlas Brasil, 2016.

Em todos os municípios, os $20 \%$ mais pobres, não conseguem ter mais que $5 \%$ do total da renda apropriada, os municípios com indicadores menores são, Cruz Machado com apenas $2,26 \%$ da renda para os $20 \%$ mais pobres, ficando abaixo da média nacional, seguido por Paula Freitas, Paulo Frontin e Bituruna, que respectivamente tem apenas 2,79\%, 3,38\% e 3,5\% ficando acima da média nacional e abaixo da média estadual. Enquanto, General Carneiro, Porto Vitória e União da Vitória ficam acima da média nacional e estadual.

Esses dados, nos apontam que mesmo a região tendo produtos que são considerados, pela mídia e poder público, como geradores de renda e emprego, percebemos que isso não está posto nos municípios, principalmente quando analisamos a taxa de pobreza, como mostra a tabela abaixo.

Tabela 8 - Taxa de pobreza (\%), Paraná e municípios da Microrregião União da Vitória - 2010

\begin{tabular}{ll}
\hline & Taxa de Pobreza (\%) \\
\hline Paraná & 6,46 \\
Bituruna & 21,04 \\
Cruz Machado & 29,04 \\
General Carneiro & 20,00 \\
Paula Freitas & 17,5 \\
Paulo Frontin & 14,24 \\
Porto Vitória & 11,48 \\
União da Vitória & 9,46 \\
\hline
\end{tabular}

Fonte: Atlas Brasil, 2016. 
A tabela 8 mostra o alto índice de pobreza nos municípios da microrregião de União da Vitória, como General Carneiro, Bituruna e Cruz Machado, que possuem respectivamente $20,00,21,04$ e $29,04 \%$ da população considerada pobre. Podemos relacionar tais dados a presença do latifúndio nos municípios, somado ao monocultivo de arvores, condicionantes que geram desemprego no campo e na cidade e consequentemente pobreza

Ainda destacamos o índice de pobreza no município de Cruz Machado, onde a taxa chega a quase $30 \%$ da população. Se comparamos esse município com a taxa de pobreza do estado do Paraná que é de 6,46\%, notamos que Cruz Machado apresenta um índice de pobreza quase 5 vezes maior que a média do estado Paraná.

O município com menor taxa de pobreza é União da Vitória, com 9,46\%. Ainda assim é maior que a média do estado, mesmo União da Vitória sendo o principal polo madeireiro da microrregião, ou seja, a monocultura de árvores não tem gerado crescimento econômico é nem social para o município, o latifúndio produtivo (monocultivo) e improdutivo se expressam como sendo o atraso na região.

Assim, entendemos que o discurso da monocultura de árvores, constantemente divulgado como gerador de divisas, se expressa de forma concentrada na região e faz parte de um processo que se mostra histórico na microrregião de União da Vitória já que a exploração da madeira nativa e da monocultura de árvores ocorre desde a Guerra do Contestado. Há mais de cem anos os camponeses da região vêm sofrendo com o processo de exploração da madeira, sendo expulsos do campo e perdendo ou sofrendo desagregação de seu modo de vida. Esse processo não termina com a guerra, de modo que se mantém com a chegada da monocultura de árvores, com a inviabilização da produção camponesa, pelo ataque de animais e nas épocas de corte da madeira pela destruição das estradas para o escoamento da mercadoria.

\section{CONSIDERAÇÕES FINAIS}

No presente artigo apresentamos breves apontamentos de uma pesquisa que ainda está no início. A microrregião de União da Vitória tem se destacado por um baixo índice de desenvolvimento, mesmo tendo como seus principais produtos os derivados da monocultura de árvores, que está entre os produtos basilares da agricultura capitalista e mesmo assim, esses importantes geradores de renda, segundo a mídia, parte da academia/intelectuais e grupos políticos locais e nacionais, não tem possibilitado melhor condição de vida para famílias que vivem na região.

Os baixos Índices de Desenvolvimento Humano Municipais (IDHM), e altas taxas de pobreza que se destacam, se comparados as médias estaduais e nacionais, apontam para 
as implicações do latifúndio improdutivo e produtivo na região no campo e na cidade. Entendemos que a relação entre a concentração de terras no campo e a presença do latifúndio produtivo e improdutivo, está diretamente ligada à pobreza das cidades e nos faz repensar a relação cidade-campo. Propalar que os desdobramentos das relações econômicas no campo, não têm repercussão na cidade, se torna algo inconciliável com a realidade.

Assim, a solução para melhorar a condição social e econômica nos municípios da microrregião de União da Vitória, passa pela necessidade de outra realidade agrária, não mais assentada na dominação do latifúndio produtivo e improdutivo e no monocultivo de árvores.

\section{REFERÊNCIAS}

ATLAS DO DESENVOLVIMENTO HUMANO NO BRASIL. Disponível em:< http://www.atlasbrasil.org.br/2013/pt/consulta/ >. Acesso 09/07/16.

IPARDES- Instituto Paranaense de Desenvolvimento Econômico e Social. Banco de dados do estado. Disponível em: <http://www.ipardes.pr.gov.br/imp/index.php>. Acesso 09/07/16

IBGE- Instituto Brasileiro de Geografia e Estatística. Disponível em:

$<$ https://sidra.ibge.gov.br/home/pms/brasil>. Acesso em 09/07/16.

FABRINI, João Edmilson. Agronegócio e latifúndio: semelhanças e diferenças no processo de acumulação de capital. Pegada, v. 1, p. 17-32, 2008.

JAPIASSU, Hilton. O mito da neutralidade científica. Rio de Janeiro, Imago Editora, 1975.

MARÉS, Carlos Frederico. A função social da terra. Porto Alegre: SAFabris, 2003.

MORAES, Antonio Carlos Robert. Geografia: Pequena História Crítica. 21를 ed. São Paulo: Anablume, 2007.

OLIVEIRA, Ariovaldo Umbelino de. A apropriação da renda da terra pelo capital na citricultura paulista. Terra Livre, AGB, v. 1, n. 1, p. 26-38, 1986.

OLIVEIRA, Ariovaldo Umbelino de. Agricultura camponesa no Brasil. 1. ed. São Paulo: Contexto, 1986.

OLIVEIRA, Ariovaldo Umbelino de. Barbárie e modernidade: as transformações no campo e o agronegócio no Brasil. Revista Terra Livre, São Paulo: AGB, ano 19, v. 2, n. 21, p. 113156, jul./dez., 2003.

OLIVEIRA, Ariovaldo Umbelino de. Geografia Agrária: perspectivas no início do século XXI. In. OLIVEIRA, Ariovaldo Umbelino de; MARQUES, Marta Inez Medeiros (orgs). O Campo no século XXI: território de vida, de luta e de construção da justiça social. São Paulo: Editora casa Amarela, 2004.

PAULINO, Eliane Tomiasi. O descumprimento da função social da terra e a invisibilização do latifúndio como estratégia de classe: o Caso de Mato Grosso. In: ALMEIDA, Rosemeire Aparecida de. SILVA, Tania Paula da. (org). Repercussões territoriais do desenvolvimento desigual-combinado e contraditório em Mato Grosso. Campo Grande: Ed. UFMS, 2015. 


\footnotetext{
${ }^{1}$ Doutorando em geografia pela Universidade Estadual de Londrina - UEL e professor temporário do curso de geografia da Universidade Estadual do Paraná - UNESPAR Campus União da Vitória. Email: silasfonseca2@gmail.com

${ }^{2}$ Sobre isso ver: FRAGA, Nilson Cesar; LUDKA, Vanessa Maria. 100 anos da Guerra do Contestado, a maior guerra camponesa na América do Sul (1912/2012): uma análise dos efeitos sobre o território sul-brasileiro. In: Anais do XII GeoCrítica. Barcelona, Espanha: Editora da UB, 2012. v. 1. p. 1-22; FRAGA, Nilson Cesar Mudanças e permanências na rede viária do Contestado: Uma abordagem acerca da formação territorial no Sul do Brasil. (Tese de Doutorado em Meio Ambiente e Desenvolvimento). Programa de Pós-Graduação em Meio Ambiente e Desenvolvimento, Universidade Federal do Paraná, Curitiba, 2006; QUEIROZ, Maurício Vinhas de. Messianismo e conflito social: a guerra sertaneja do Contestado (1912-1916). - Rio de Janeiro: Editora Civilização Brasileira, 1966.

3 Disponível em: http://www.cepea.esalq.usp.br/br. Acesso em 20 de janeiro de 2017.

${ }^{4}$ Como exemplo cita-se, OLIVEIRA, Ariovaldo U. de. Barbárie e modernidade: as transformações no campo e o agronegócio no Brasil. Revista Terra Livre, São Paulo: AGB, ano 19, v. 2, n. 21, p. 113156, jul./dez., 2003.
} 